\title{
Structural analysis of asparaginyl endopeptidase reveals the activation mechanism and a reversible intermediate maturation stage
}

Lixia Zhao ${ }^{1,2,{ }^{*}}$, Tian Hua ${ }^{1, *}$, Christopher Crowley ${ }^{3}$, Heng $\mathrm{Ru}^{1}$, Xiangmin $\mathrm{Ni}^{1}$, Neil Shaw ${ }^{1}$, Lianying Jiao ${ }^{1}$, Wei Ding ${ }^{1}, \mathrm{Lu} \mathrm{Qu}^{1}, \mathrm{Li}-\mathrm{Wei} \mathrm{Hung}^{4}$, Wei Huang ${ }^{2}$, Lei Liu ${ }^{5}$, Keqiang Ye ${ }^{6}$, Songying Ouyang ${ }^{1}$, Genhong Cheng ${ }^{3}$, Zhi-Jie Liu ${ }^{1,2}$

${ }^{I}$ National Laboratory of Biomacromolecules, Institute of Biophysics, Chinese Academy of Sciences, Beijing 100101, China; ${ }^{2} i H u-$ man Institute, ShanghaiTech University, Shanghai 201210, China; ${ }^{3}$ Department of Microbiology, Immunology and Molecular Genetics, University of California Los Angeles, Los Angeles, CA 90095, USA; ${ }^{4}$ Physics Division, Los Alamos National Laboratory, Los Alamos, NM 87545, USA, ${ }^{5}$ Key Laboratory of Bioorganic Phosphorus Chemistry \& Chemical Biology (Ministry of Education), Department of Chemistry, Tsinghua University, Beijing 100084, China; ${ }^{6}$ Department of Pathology and Laboratory Medicine, Emory University School of Medicine, Atlanta, GA 30322, USA

Asparaginyl endopeptidase (AEP) is an endo/lysosomal cysteine endopeptidase with a preference for an asparagine residue at the P1 site and plays an important role in the maturation of toll-like receptors 3/7/9. AEP is known to undergo autoproteolytic maturation at acidic $\mathrm{pH}$ for catalytic activation. Here, we describe crystal structures of the AEP proenzyme and the mature forms of AEP. Structural comparisons between AEP and caspases revealed similarities in the composition of key residues and in the catalytic mechanism. Mutagenesis studies identified N44, R46, H150, E189, C191, S217/S218 and D233 as residues that are essential for the cleavage of the peptide substrate. During maturation, autoproteolytic cleavage of AEP's cap domain opens up access to the active site on the core domain. Unexpectedly, an intermediate autoproteolytic maturation stage was discovered at approximately $\mathrm{pH} 4.5$ in which the partially activated AEP could be reversed back to its proenzyme form. This unique feature was confirmed by the crystal structure of $\mathrm{AEP}_{\mathrm{pH} 4.5}$ (AEP was matured at $\mathrm{pH} 4.5$ and crystallized at $\mathrm{pH} 8.5$ ), in which the broken peptide bonds were religated and the structure was transformed back to its proenzyme form. Additionally, the AEP inhibitor cystatin $C$ could be digested by the fully activated AEP, but could not be digested by activated cathepsins. Thus, we demonstrate for the first time that cystatins may regulate the activity of AEP through substrate competition for the active site.

Keywords: asparaginyl endopeptidase; autoproteolytic maturation; crystal structure; innate immunity Cell Research (2014) 24:344-358. doi:10.1038/cr.2014.4; published online 10 January 2014

\section{Introduction}

*These two authors contributed equally to this work. Correspondence: Zhi-Jie Liu ${ }^{\mathrm{a}}$, Genhong Cheng ${ }^{\mathrm{b}}$, Songying Ouyang ${ }^{\mathrm{c}}$

${ }^{\mathrm{a}}$ Tel: + 86-10-64857988; Fax: + 86-10-64888426

E-mail: zjliu@ibp.ac.cn

${ }^{\mathrm{b}}$ Tel: 310-825-8896; Fax: 310-206-5553

E-mail: gcheng@mednet.ucla.edu

${ }^{\mathrm{c}}$ Tel: + 86-10-64888252; Fax: + 86-10-64888426

E-mail: ouyangsy@moon.ibp.ac.cn

Received 12 July 2013; revised 17 September 2013; accepted 5 November

2013; published online 10 January 2014
Mammalian asparaginyl endopeptidase (AEP) or legumain (EC 3.4.22.34) is a lysosomal cysteine endopeptidase that specifically cleaves substrates with an asparagine or aspartate residue at the P1 site [1]. It has been detected in heart, spleen, liver, brain and testis tissues, but it is particularly abundant in the kidney and placenta [2]. AEP is predominantly localized in the late endosomes and lysosomes [2] and belongs to the $\mathrm{C} 13$ peptidase family. AEP is unrelated to the papain-like $\mathrm{C} 1$ family of lysosomal-cysteine proteases, such as the cathepsins $\mathrm{S}$, $\mathrm{B}, \mathrm{L}$ and $\mathrm{H}$, but has features that suggest an evolutionary relationship to caspases, the bacterial proteases gingipain 
and clostripain and separase [3].

The inactive full-length pro-AEP can be activated by shifting the $\mathrm{pH}$ from neutral to acidic. AEP appears to be autocatalytically cleaved after asparagine or aspartate residue. AEP is also involved in the proteolytic maturation of pro-cathepsins $\mathrm{B}, \mathrm{H}$ and $\mathrm{L}$ found in the endo/lysosomes [4]. In addition to the cathepsins, AEP also processes fibronectin [5], pro-gelatinase A [6] and $\alpha$-thymosin [7].

Cystatin $\mathrm{C}$ is a secreted type 2 cysteine proteinase inhibitor and exerts effects on multifarious cysteine proteases including papain and cathepsins B, H, K, L and S. As the most abundant extracellular inhibitor of cysteine proteases, cystatin $\mathrm{C}$ is encoded by a housekeeping gene and is found ubiquitously in all organs and biological fluids at high concentration levels. Cystatin $\mathrm{C}$ can also inhibit AEP activity [8]. However, the inhibitory mechanisms are still elusive.

AEP is known to play a role in the processing of antigens for MHC class II presentation in the lysosomes of antigen presenting cells [2, 9-11]. More recently, AEP has been reported to regulate innate immune responses via its participation in the maturation of the toll-like receptors (TLRs) 3, 7 and 9 [12-14]. These TLRs undergo proteolytic maturation, which is required for their downstream signaling events [15]. A $72 \mathrm{kDa} C$-terminal fragment of TLR9 that is generated by proteolytic cleavage associates with the adaptor molecule MyD88 and initiates the production of pro-inflammatory cytokines and other co-immunostimulatory molecules [16].

Intriguingly, in addition to its known roles in catalyzing peptide bond cleavage, AEP is also responsible for ligation of cyclotides via transpeptidation reactions in a single processing event [17]. To date, there are at least three examples of AEP-mediated formation of cyclic peptides in phylogenetically distant plants [18], such as kalata B1 from Oldenlandia affinis (Rubiaceae) and cycloviolacin O11 from Viola odorata (Violaceae). However, little is known about the mechanism of AEP-mediated cyclic peptide formation. Additionally, the ligation properties of AEP have not yet been observed in mammalian systems.

Here, we describe crystal structures of the proenzyme and the mature forms of mouse AEP, which clearly illustrate the basis for the inability of the proenzyme to perform catalysis. We show that the maturation of AEP requires the removal of a cap that covers the active site. This process is reversible and $\mathrm{pH}$-dependent. Structurebased mapping of the active site residues using sitedirected mutagenesis suggests a cysteine endopeptidasetype catalytic mechanism that is similar to that observed for caspases.

\section{Results}

Characterization of the proenzyme and mature forms of AEP

Initially, human and mouse AEPs ( $83 \%$ sequence identity) were selected for structural and functional analyses (Figure 1A). Both proteins were expressed in insect cells, and the secreted proteins in the cell culture supernatants were collected and purified as soluble proteins (Supplementary information, Figure S1A). The subsequent structure-based experiments were primarily focused on mouse AEP; therefore, unless specified, AEP refers to mouse AEP hereafter. The theoretical molecular weight (MW) of pro-AEP without the signal peptide (residues 18-435) is $\sim 47 \mathrm{kDa}$ (Figure 1B). Mass spectrometry analysis of pro-AEP produced in insect cells and purified at $\mathrm{pH} 7.5$ indicated a MW of $53.3 \mathrm{kDa}$ (Supplementary information, Figure S1B). This result combined with those from endoglycosidase treatment suggested that pro-AEP was probably glycosylated (Supplementary information, Figure S1C).

The endopeptidase activity of AEP was measured using Z-AAN-NHMec as the substrate. As the $\mathrm{pH}$ of the incubation buffer decreased from neutral to below 5.0, the endopeptidase activity of AEP gradually increased, which peaked (full activity) at approximately $\mathrm{pH} 3.5$ and then dramatically decreased as the $\mathrm{pH}$ further decreased (Figure 1C). The activity of AEP towards the substrate Z-AAN-NHMec was inhibited by the AAN-CMK inhibitor [19] (Supplementary information, Figure S2A). Additionally, both fully activated AEP at $\mathrm{pH} 3.5\left(\mathrm{AEP}_{\mathrm{pH} 3.5}\right)$ and partially activated AEP at $\mathrm{pH} 4.5\left(\mathrm{AEP}_{\mathrm{pH} 4.5}\right)$ were able to cleave recombinant protein GST-TEV-ubiquitin $(\mathrm{Ub})$ at the asparagine $(\mathrm{N})$ site, as identified by N-terminal sequencing (Supplementary information, Figure S2B and $\mathrm{S} 2 \mathrm{C}$ ).

To investigate the oligomerization and autocleavage status of AEP during the autoactivation process, several biochemical and biophysical methods were employed. The size exclusion chromatography (SEC) elution profile (Supplementary information, Figure S1D) indicated that pro-AEP forms a homodimer at neutral $\mathrm{pH}$. To verify the oligomeric state of pro-AEP in solution, we performed small-angle X-ray scattering (SAXS) analysis, which confirmed that the protein exists as a homodimer in solution (Supplementary information, Figure S3). Furthermore, SDS-PAGE analysis of pro-AEPs that were incubated under different $\mathrm{pH}$ conditions revealed that the autoproteolytic maturation of pro-AEP was $\mathrm{pH}$-dependent (Figure 1D). Interestingly, when pro-AEP was activated at $\mathrm{pH} 5.5-4.5, \mathrm{a} \sim 36 \mathrm{kDa}$ band corresponding to the core domain and several bands of $\sim 13 \mathrm{kDa}$ corresponding 
to the C-terminal domain (CTD) appeared in the SDSPAGE gel, indicating that the peptide bonds linking the two domains were cleaved at multiple sites (Figure 1D). However, at this stage, $\mathrm{AEP}_{\mathrm{pH} 4.5}$ exhibited only partial activity (Figure 1C) and was eluted at the same time as pro-AEP in the SEC elution profile, indicating that the cleaved CTD remained associated with the core domain (Supplementary information, Figure S1D). In contrast, $\mathrm{AEP}_{\mathrm{pH} 3.5}$ and $\mathrm{AEP}_{\mathrm{pH} 4.0}$ were eluted as monomers in SEC analysis (Supplementary information, Figure S1D and S1E). SDS-PAGE analysis revealed that the bands of approximately $13 \mathrm{kDa}$ corresponding to the CTD disappeared when the $\mathrm{pH}$ was decreased from 4.5 to 4.0 (Figure 1D). This result suggests that the CTD of pro-AEP began to dissociate from the core domain and presumably was degraded when the $\mathrm{pH}$ was decreased below 4.5. Collectively, these results suggest that AEP activated at a $\mathrm{pH}$ below 4.5 existed as a monomer in solution, whereas pro-AEP existed as a homodimer, the formation of which was probably mediated by the CTD.

When the autocleavage sites were further investigated using $\mathrm{N}$-terminal amino acid sequencing, two new
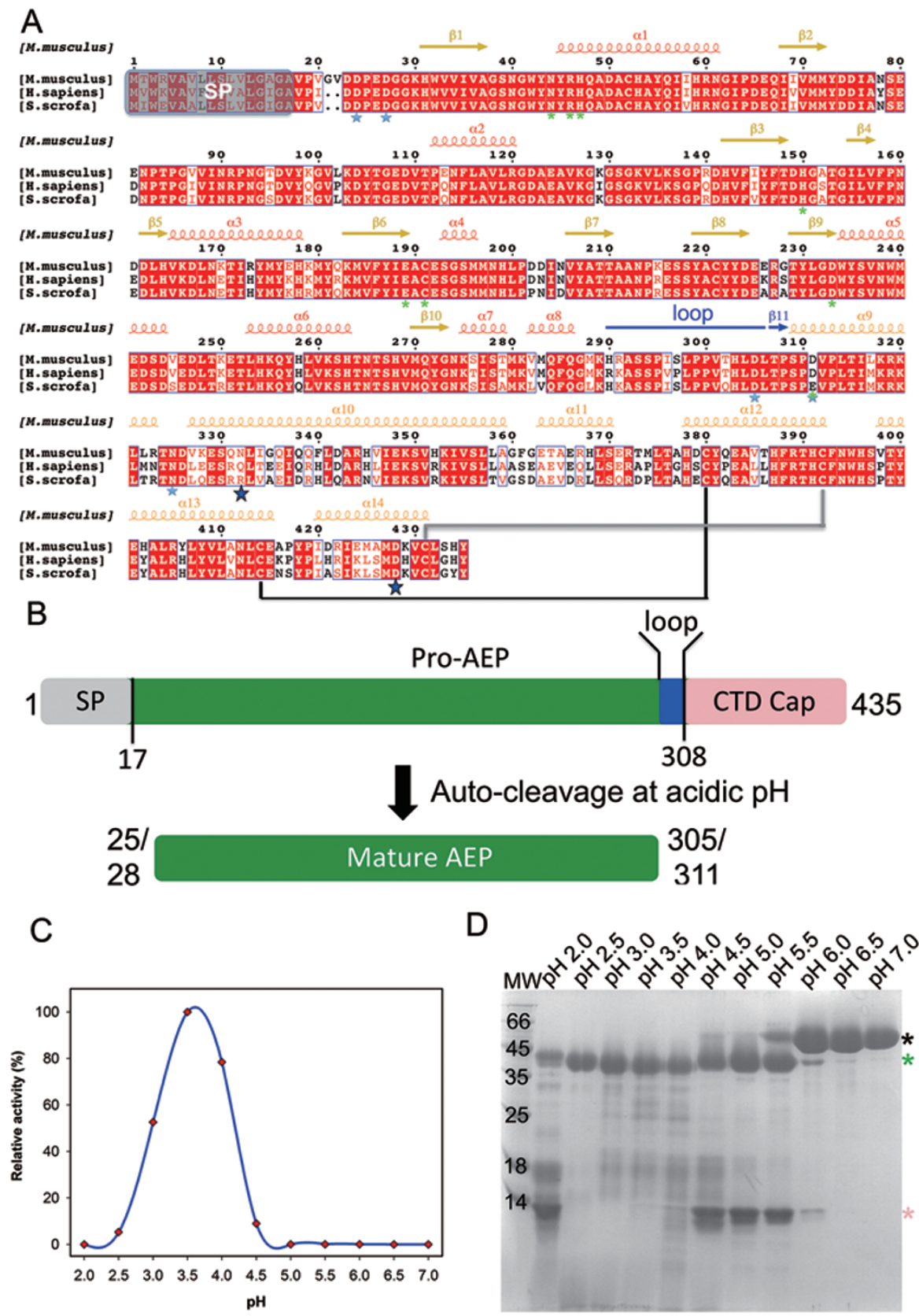
Figure 1 Characterization of the proenzyme and mature forms of AEP. (A) Multiple sequence alignment of AEP, which includes the secondary structure elements based on the AEP structure at $\mathrm{pH} 7.5$ (refer to Figure 2B). Strictly conserved residues are boxed in white on a red background and highly conserved residues are boxed in red on a white background. The secondary structure elements of mouse AEP are shown above the sequences and every ten residues are indicated with a dot $(\cdot)$. Previously reported cleavage sites and two newly identified sites in this study are indicated with marine and blue fivepointed stars, respectively. Key residues for AEP activity are indicated with green asterisks. Two disulfide bonds in the cap domain are indicated with black and grey lines. SP: signal peptide. The alignment was generated using ClustalW. $\alpha$-Helices are depicted as coils, and $\beta$-strands are depicted as arrows. The figure was generated using ESPript (http://espript.ibcp.fr/ESPript/ESPript/). (B) Domain organization of mouse AEP and its autocleavage at acidic $\mathrm{pH}$. The numbers indicate residues at the domain boundaries. SP: signal peptide (residues 1-17); CTD cap: the C-terminal cap domain; and Mature AEP: the core domain. (C) The relative endopeptidase activity of AEPs was measured by using Z-AAN-NHMec as the substrate. AEPs were activated by incubation under different $\mathrm{pH}$ conditions overnight at $16{ }^{\circ} \mathrm{C}$. (D) The $\mathrm{pH}$-dependent autoproteolytic activation of human pro-AEP illustrated using SDS-PAGE analysis. Pro-AEP that was purified at $\mathrm{pH} 7.5$ was incubated at the indicated $\mathrm{pH}$ (citric acid buffer), which ranged from $\mathrm{pH} 7.0$ to 2.0 , at $16{ }^{\circ} \mathrm{C}$ for $16 \mathrm{~h}$. MW: molecular weight marker. Black, green, and wheat asterisks represent the pro-AEP, AEP core domain, and AEP CTD, respectively.

sites, N332 and D428, were identified in addition to the previously reported N325, D24 and D27 sites [20, 21] (Supplementary information, Figure S1F). However, two previously reported autocleavage sites, D305 and D311 [22], were not detected in this study.

\section{Structure of $A E P_{p H 3.5}$}

To study the molecular basis of the AEP activation process, we determined and compared the crystal structures of AEPs that were processed under different $\mathrm{pH}$ conditions. The pro-AEP purified at $\mathrm{pH} 7.5\left(\mathrm{AEP}_{\mathrm{pH} 7.5}\right)$ was incubated at $\mathrm{pH} 3.5\left(\mathrm{AEP}_{\mathrm{pH} 3.5}\right)$ for complete activation. $\mathrm{AEP}_{\mathrm{pH} 3.5}$ was crystallized at $\mathrm{pH} 6.7$, and the crystal diffracted to a resolution of $2.80 \AA$ (Table 1). The structure of $\mathrm{AEP}_{\mathrm{pH} 3.5}$ (residues K30-Q289) consists of only the core domain (Figure 2A). The CTD seems to have dissociated from the core domain after autoproteolytic processing at $\mathrm{pH} 3.5$. The core domain consists of a central sheet composed of six strands of which five $(\beta 1, \beta 2$, $\beta 3, \beta 6$ and $\beta 7$ ) are parallel with a sixth short antiparallel strand $(\beta 10)$. The central sheet appears to be flanked by helices on both sides (Figure 2A). Dali [23] and ProFunc [24] analyses identified caspases, particularly caspases 3, 7, 8 and 9, as the closest structural matches; for example, an RMSD of $1.96 \AA$ over 167 residues was obtained for caspase 3 (PDB ID: 4EHK) [25]. The largest difference was observed at a long loop (Y73-T111) between the $\beta 2$ strand and $\alpha 2$-helix. Two other distinct differences were observed between the $\alpha 2$-helix and $\beta 3$-strand (L23) and between the $\beta 7$-strand and $\alpha 5$-helix (L75) (Supplementary information, Figure S4). These caspases use a catalytic dyad that consists of a histidine (H121 in caspase 3) and a cysteine (C163 in caspase 3 ) for proteolytic processing. Superposition of the caspase structures with AEP structure identified a pair of amino acids, i.e., H150 and C191, as a potential catalytic dyad (Figure 2A). This pair of residues is located on the surface of AEP and appears to be accessible (Figure 2A). It is known that a carbonyl oxygen actively participates in the catalysis of caspases [26], such as the carbonyl oxygen of G122 in caspase 3. The carbonyl oxygen atom of N44, D149, G151, E189, S218, or D233 in AEP is within hydrogen-bonding distance of the catalytic dyad (H150 and C191) and may serve as an oxyanion hole for substrate accommodation (Figure 2A). Additionally, a structural comparison between $\mathrm{AEP}_{\mathrm{pH} 3.5}$ and the complex of caspase 3 and its inhibitor Ac-DEVD-CMK (PDB ID: 4EHK) revealed that R46, H47 and E189-E192 contribute to the formation of the S1 pocket and that two $\beta$-strands ( $\beta 8$ and $\beta 9$ ) located between the $\beta 7$-strand and $\alpha 5$-helix probably contribute to substrate recognition (Supplementary information, Figure S4). Interestingly, this comparison also revealed that the loop L47 between the $\alpha 4$-helix and $\beta 7$-strand sterically hinders dimer formation of mature AEPs (Supplementary information, Figure S4).

\section{Structures of $A E P_{p H 7.5}$ and $A E P_{p H 4.5}$}

The structures of $\mathrm{AEP}_{\mathrm{pH} 7.5}$ and $\mathrm{AEP}_{\mathrm{pH} 4.5}$ were determined at 2.49 and $2.0 \AA$ resolution, respectively (Table 1). $\mathrm{AEP}_{\mathrm{pH} 7.5}$ was crystallized at $\mathrm{pH} 7.0$ and adopts a fold composed of $14 \alpha$-helices and $11 \beta$-sheets (Figure 2B). The overall structure of $\mathrm{AEP}_{\mathrm{pH} 7.5}$ is distinctly divided into two parts: a $\alpha / \beta$-core domain (K30-Q289) that exhibits a TIM-barrel fold, and an entirely $\alpha$-helical cap domain (S309-S435) that is located directly above the conserved catalytic surface of the core domain, and is similar to the death effector domain of caspases. Two pairs of internal disulfide bonds further stabilize the cap domain (Figures $2 \mathrm{~B}$ and $1 \mathrm{~A}$ ). The cap domain is linked to the core domain via a long loop (G290-P308) (Figure 2B and 2C). In addition, the cap domain interacts with the core domain through extensive direct or solvent-mediated hydrogen bonds, as well as salt bridges (Supplementary information, Figure S5A, Tables S1 and S2 ). The link- 
A

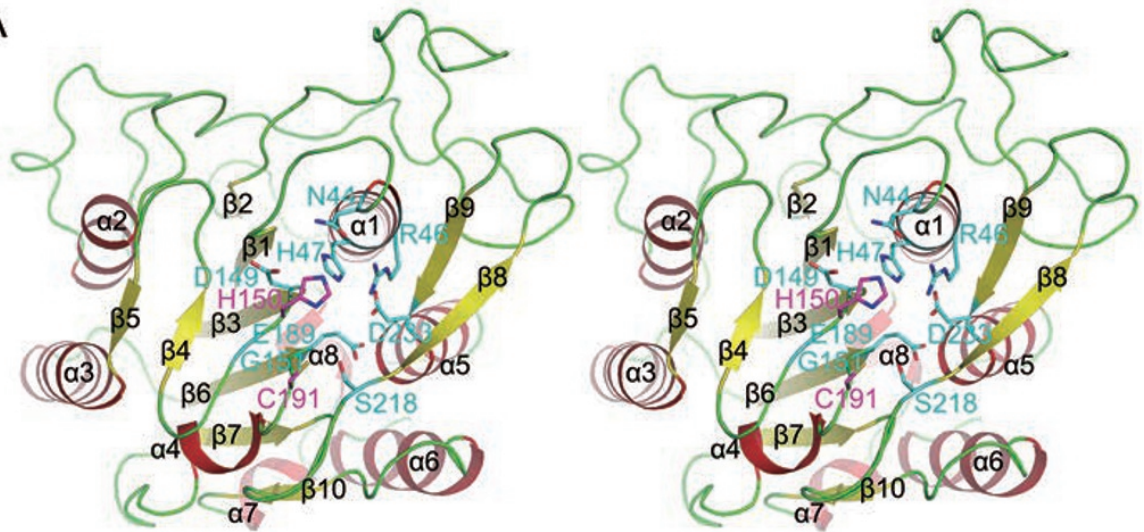

B

C

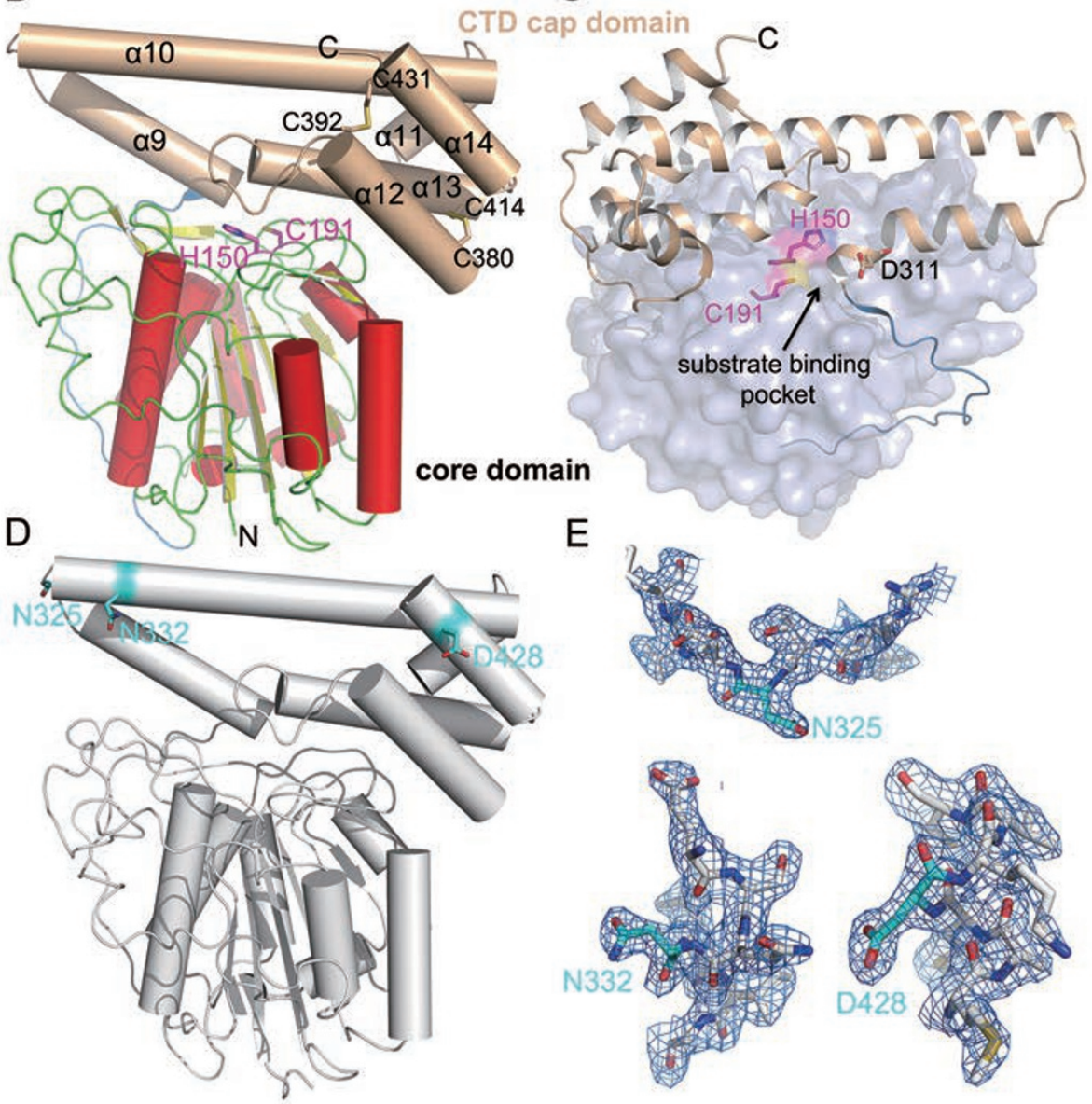

Figure 2 Overall structures of the mature AEP and pro-AEP. (A) Walleye stereoview of the structure of AEP $\mathrm{pH}_{3.5}$. Key residues are shown as sticks. $\beta$-strands and $\alpha$-helices are numbered. (B) The overall bimodular structure of the pro-AEP at $\mathrm{pH}$ 7.5 composed of the core domain and the entirely $\alpha$-helical cap domain that is depicted as a cylindrical model ( $\alpha$-helices are numbered from $\alpha 9-\alpha 14$, wheat). The active site, including the key residues $\mathrm{H} 150$ and $\mathrm{C} 191$, is covered by the cap domain. The long loop that connects the core domain and the cap domain is colored blue. The residues that form two pairs of internal disulfide bonds (C380 in $\alpha 12$ and C414 in $\alpha 13$, C392 in $\alpha 12$ and C431 in $\alpha 14)$ in the cap domain are labeled. The Nand C-termini of each chain are labeled with the respective letters. (C) The indicated cavity (arrow) represents the potential substrate-binding pocket. The linkage area between the cap domain (wheat) and the long loop (blue) sterically obstructs substrate access to the active site. (D) The overall structure of activated $\mathrm{AEP}_{\mathrm{pH} 4.5}$ (crystallized at pH 8.5), which is similar to the structure of $A E P_{\mathrm{pH} 7.5}$. The key cleavage sites were indicated as cyan sticks. (E) The $2.0 \AA 2 \mathrm{~F}_{\mathrm{o}}-\mathrm{F}_{\mathrm{c}}$ omit electron density map countered at $2.0 \sigma$ for residues $30-435$ is complete without breaks at either the previously reported cleavage site (N325) or the new cleavage sites of N332 and D428 identified using N-terminal amino acid sequencing in this study. 
Table 1 Data collection and refinement statistics

\begin{tabular}{|c|c|c|c|c|}
\hline AEP Derivatization & $\mathrm{AEP}_{\mathrm{pH} 4.5}$ (Hg-derivatization) & $\mathrm{AEP}_{\mathrm{pH} 7.5}$ & $\mathrm{AEP}_{\mathrm{pH} 3.5}$ & AEP D233 $\mathrm{A}_{\mathrm{pH} 7.5}$ \\
\hline \multicolumn{5}{|l|}{ Data collection } \\
\hline X-ray source & BL17U(SSRF) & BL17A(KEK) & BL17U(SSRF) & BL17U(SSRF) \\
\hline Space group & $\mathrm{P} 2{ }_{1} 2_{1} 2$ & $\mathrm{P} 22_{1} 2$ & $\mathrm{P} 2{ }_{1} 2_{1} 2_{1}$ & $\mathrm{P} 2_{1}$ \\
\hline \multicolumn{5}{|l|}{ Unit cell dimensions } \\
\hline Resolution range $(\AA)$ & $50.00-2.00(2.15-2.00)$ & $50.00-2.49(2.59-2.49)$ & $50.00-2.80(2.90-2.80)$ & $50.00-2.70(2.80-2.70)$ \\
\hline$R_{\text {sym }}(\%)$ & $0.07(0.43)$ & $0.08(0.49)$ & $0.127(0.495)$ & $0.08(0.48)$ \\
\hline 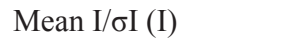 & $33.03(4.00)$ & $45.09(2.45)$ & $12.29(2.20)$ & $13.79(2.38)$ \\
\hline Completeness (\%) & $93.00(65.90)$ & $85.90(56.20)$ & $97.00(95.10)$ & $99.00(99.80)$ \\
\hline No. of reflections & 32142 & 17063 & 8038 & 23903 \\
\hline$R_{\text {work }} / R_{\text {free }}(\%)$ & $20.44 / 24.28$ & $20.22 / 25.19$ & $23.27 / 29.40$ & $21.67 / 27.52$ \\
\hline \multicolumn{5}{|l|}{ No. of atoms } \\
\hline Protein & 3266 & 3247 & 2088 & 6190 \\
\hline Water & 158 & 128 & 26 & 83 \\
\hline Mean B value $\left(\AA^{2}\right)$ & 45.72 & 31.11 & 51.70 & 24.95 \\
\hline \multicolumn{5}{|l|}{ R.m.s deviations } \\
\hline Bond lengths ( $\AA$ ) & 0.007 & 0.003 & 0.006 & 0.003 \\
\hline Bond angles $\left(^{\circ}\right)$ & 1.042 & 0.776 & 0.992 & 0.804 \\
\hline
\end{tabular}

Numbers in parentheses represent the statistics for the highest resolution shell.

age area between the cap domain (wheat) and the long loop (blue) sterically obstructs substrate access to the nearby substrate-binding pocket of the core domain (Figure $2 \mathrm{C}$ ). The negatively charged surface of the active site is neutralized by the positively charged interface of the cap domain under neutral $\mathrm{pH}$ conditions (Supplementary information, Figure S5B). This observation may explain the stability of pro-AEP under neutral $\mathrm{pH}$ conditions, whereas under acidic $\mathrm{pH}$ conditions, the surface of the active site would be protonated following the disassociation of the cap domain from the core domain. Although the asymmetric unit contained one molecule of pro-AEP, analysis of the symmetry mates revealed that pro-AEP was crystallized as a dimer (Supplementary information, Figure S5C). The intermonomer interactions are hydrophobic and are mediated by L321, L333, I334, I337 and L341 of the C-terminal cap domains (Supplementary information, Figure S5C), which form homotypic interactions. Thus, the packing of pro-AEP as a dimer in the crystal lattice is consistent with its oligomeric state in solution.

Superposition of the structure of the mature, active AEP with the structure of the AEP proenzyme revealed that the core domain did not undergo significant conformational changes upon activation. Superposition of the $\mathrm{C} \alpha$ atoms of the mature enzyme with those of the proAEP resulted in an RMSD of $0.34 \AA$ over 248 residues (Supplementary information, Figure S5D). Because the mature, active AEP contained only the core domain, the cap domain observed in the structure of the inactive proAEP may sterically occlude access to the active site in the core domain.

To explore the activation process of AEP, we attempted to determine the crystal structure of $\mathrm{AEP}_{\mathrm{pH} 4.5}$, which 
represents the turning point in the activation process. Unexpectedly, $\mathrm{AEP}_{\mathrm{pH} 4.5}$ that was activated at $\mathrm{pH} 4.5$ (in a buffer containing $20 \mathrm{mM}$ citric acid, $\mathrm{pH} 4.5$ and $150 \mathrm{mM}$ $\mathrm{NaCl}$ ) and crystallized at $\mathrm{pH} 8.5$ exhibited an identical architecture as $\mathrm{AEP}_{\mathrm{pH7.5}}$ (Figure 2D). The electron density omit map for residues 30-435 did not contain breaks at either the previously reported cleavage sites (such as N325) or the two newly identified cleavage sites, N332 and D428 (Figure 2D and 2E). All the structural elements of the three forms of AEPs $\left(\mathrm{AEP}_{\mathrm{pH} 7.5}, \mathrm{AEP}_{\mathrm{pH} 4.5}\right.$ and $\left.\mathrm{AEP}_{\mathrm{pH} 3.5}\right)$ could be superposed with virtually no differences in the positions of the main-chain atoms (Supplementary information, Figure S5D).

The crystal structure of $\mathrm{AEP}_{\mathrm{pH} 4.5}$ unveiled a striking phenomenon: the broken peptide bonds at $\mathrm{pH} 4.5$ "healed" under the basic crystallization condition $(\mathrm{pH} 8.5)$, which resulted in the transformation of the partially activated $\mathrm{AEP}_{\mathrm{pH} 4.5}$ back to its pro-AEP form. To eliminate the possibility of sample misplacement or contamination, a new batch of $\mathrm{AEP}_{\mathrm{pH} 4.5}$ was prepared, and the SDS-PAGE analysis (revealed cleaved fragments), crystallization ( $\mathrm{pH}$ 8.5), data collection and structure determination were carefully repeated. An identical crystal structure was obtained.

\section{Proteolytic activation of AEP is reversible}

To further confirm this new discovery, an aliquot of $\mathrm{AEP}_{\mathrm{pH} 4.5}$, which exhibited a $\sim 36 \mathrm{kDa}$ band corresponding to the core domain and several additional bands $(\sim 13$ $\mathrm{kDa}$ ) in the SDS-PAGE gel (Figure 3A, lane $\mathrm{pH} 4.5$ ), was diluted in a series of buffers of elevated $\mathrm{pH}$ values (5.0-7.5) and incubated overnight at $16{ }^{\circ} \mathrm{C}$. As expected, as the $\mathrm{pH}$ increased, AEP gradually reversed back into its pro-AEP form (Figure 3A). To further cross-validate this reversion, the samples were then analyzed by western blot using an anti-His antibody, which recognizes the $6 \times$ His tag at the cap domain of pro-AEP (Supplementary information, Figure S5E). The result indicated that the Cterminal fragments $(\sim 13 \mathrm{kDa})$ generated during autoproteolysis were gradually re-ligated to form the proenzyme when the $\mathrm{pH}$ was increased towards 7.5 (Figure 3B). We then expressed AEP in HEK293 cells, and activated the purified AEP at $\mathrm{pH}$ 4.5. These activated AEP proteins could also be reversed to their proenzyme forms (Supplementary information, Figure S6). However, we found that AEP was not reversed to its proenzyme form if the activation $\mathrm{pH}$ was below 4.0 (Supplementary information, Figure S7A and Table S3).

Collectively, these results indicate that at an incubation $\mathrm{pH}$ of approximately 4.5 , pro-AEP is partially activated and the cap domain remains associated with the core domain probably via non-covalent interactions, such
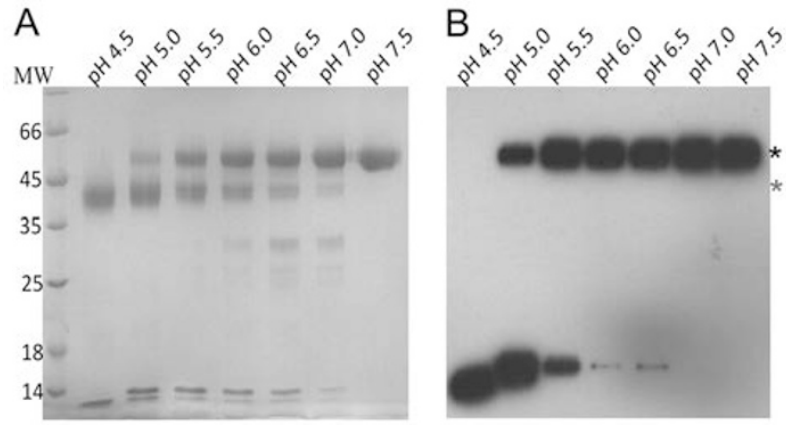

Figure 3 The proteolytic activation of AEP at a $\mathrm{pH} \geq 4.5$ is reversible. (A) SDS-PAGE analysis of partially activated AEP incubated at different $\mathrm{pH}$ values. $\mathrm{AEP}_{\mathrm{pH} 4.5}$ was diluted in citric buffer at the indicated $\mathrm{pH}(5.0-7.5)$ and incubated for $16 \mathrm{~h}$ at $16{ }^{\circ} \mathrm{C}$. (B) Western blot analysis of samples from A visualized using an anti-His antibody, which recognizes the C-terminal 6x His-tag of pro-AEP. Black and grey asterisks represent pro-AEP and mature AEP (the core domain), respectively.

as extensive salt bridges and direct or solvent-mediated hydrogen bonds, even though the peptide bond has been cleaved. However, at a $\mathrm{pH}$ below 4.0, the cap domain disassociates and consequently is degraded. Therefore, AEP can no longer be reversed to its proenzyme form. The core domain is fully activated at this stage.

\section{Residues involved in the endopeptidase activity of AEP}

We performed alanine-scanning mutagenesis of the conserved residues that were identified by a primary sequence alignment (Supplementary information, Figure S8). To ensure that these AEP mutants were correctly folded, 13-AEP mutants (D27A/N325A, S39A, N44A, R46A, H47A, V110A, D149A, H150A, E189A, C191A, S217A/S218A, D233A and D311A) and wild-type (WT) AEP, each prepared in a $\mathrm{pH} 7.5$ buffer, were analyzed using circular dichroism (CD) spectroscopy. The CD analysis indicated that the mutants possessed similar secondary structures as WT AEP, except for H150A, which exhibited slight differences (Supplementary information, Figure S9). Additionally, the SEC profiles of all the mutants overlapped well with that of WT AEP.

Next, we evaluated the effect of the AEP mutations on its endopeptidase activity against the peptide substrate Z-AAN-NHMec. The mutants were activated at $\mathrm{pH} 3.5$ overnight at $16{ }^{\circ} \mathrm{C}$, and their relative activities were evaluated under the conditions described in the Materials and Methods. Substitution of the absolutely conserved H150 or C191 with alanine completely abolished the enzymatic activity (Figure 4A and Supplementary information, Table S3), suggesting a critical role of these amino 
acids in catalysis. Interestingly, substitution of N44, R46, E189, or D233 with alanine also resulted in an almost complete loss of activity. Mutants S39A, H47A, D149A and $\mathrm{S} 217 \mathrm{~A} / \mathrm{S} 218 \mathrm{~A}$ exhibited a dramatic decrease in the activity of the enzyme (to less than $20 \%$ of the WT AEP activity). The V110A, P159A and C221A mutants exhibited only $21.9 \%, 38.8 \%$ and $49.9 \%$ of WT AEP activities, respectively. However, the S309A and E80A/E81A mutants retained approximately $80 \%$ of the WT AEP activity. The activities of the E192A, N213A and E401A mutants were barely altered in comparison with that of WT AEP (Figure 4A, 4B and Supplementary information, Table S3). The Y45A, E216A, Y222A/Y223A and S267A/H268A mutants did not exhibit any activity due to protein degradation in the $0.2 \mathrm{M}$ citrate buffer at $\mathrm{pH}$ 3.5 or 4.0 during the activation process (Supplementary information, Figure S7G).

The residues D27, D305, D311 and N325 of AEP are known as autoproteolytic cleavage sites [20-22]. Substitution of D27 with alanine slightly decreased the enzymatic activity. This result is consistent with our structural study showing that D27 does not lie near the center of the active site (Figure 4C). It is also consistent with previous reports indicating that D27 is not essential for the AEP activity $[22,27]$. In contrast, the activities of both the N325A and the D27A/N325A mutants decreased significantly (Figure 4A, 4C and Supplementary information, Table S3). Interestingly, D305A and D311A mutants exhibited $84.4 \%$ and $3.4 \%$ activity, respectively. The structure of $\mathrm{AEP}_{\mathrm{pH} 7.5}$ indicates that D305 and D311 are located in the linker region between the core and cap domains. However, D311 sits at the turning point of a sharp turn pointing into the substrate-binding pocket and lies closer to the pocket than D305 (Figure 2C). Therefore, we speculate that D311 was more likely to be autoproteolytically cleaved to initiate AEP activity, and thus its mutation affects the activity of AEP to a greater extent than the mutation of D305.

Collectively, the structural analyses and mutagenesis studies suggest that N44, R46, H150, E189, C191, S217, S218 and D233 seem to form the active site and are essential for the cleavage of the peptide substrate. As for the autoproteolytic cleavage sites, the N-terminal cleavage site D27 is not required for the enzymatic activity. However, the C-terminal cleavage sites, D311 and N325, are essential for AEP activity.

\section{Residues involved in the autoproteolytic maturation of AEP}

To identify the residues involved in the autoproteolytic maturation of AEP, we performed an overnight incubation of pro-AEP mutants (prepared at $\mathrm{pH}$ 7.5) in buffers of $\mathrm{pH} 4.5$ and 4.0. These samples were then examined by SDS-PAGE analyses (Supplementary information, Figure S7A-S7G). Activated, matured AEP exhibited as a band of lower molecular weight on the SDS-PAGE gel in comparison to its full-length proenzyme form. Intriguingly, the N44A, R46A, E189A and C191A mutants, which did not exhibit any activity against the peptide substrate ZAAN-NHMec when exposed to $\mathrm{pH} 3.5$ (Figure 4A and Supplementary information, Table S3), could still be autoproteolytically digested to their mature forms. However, the human AEP C189S mutant (C189 corresponds to $\mathrm{C} 191$ in mouse AEP) was reported to be unable to
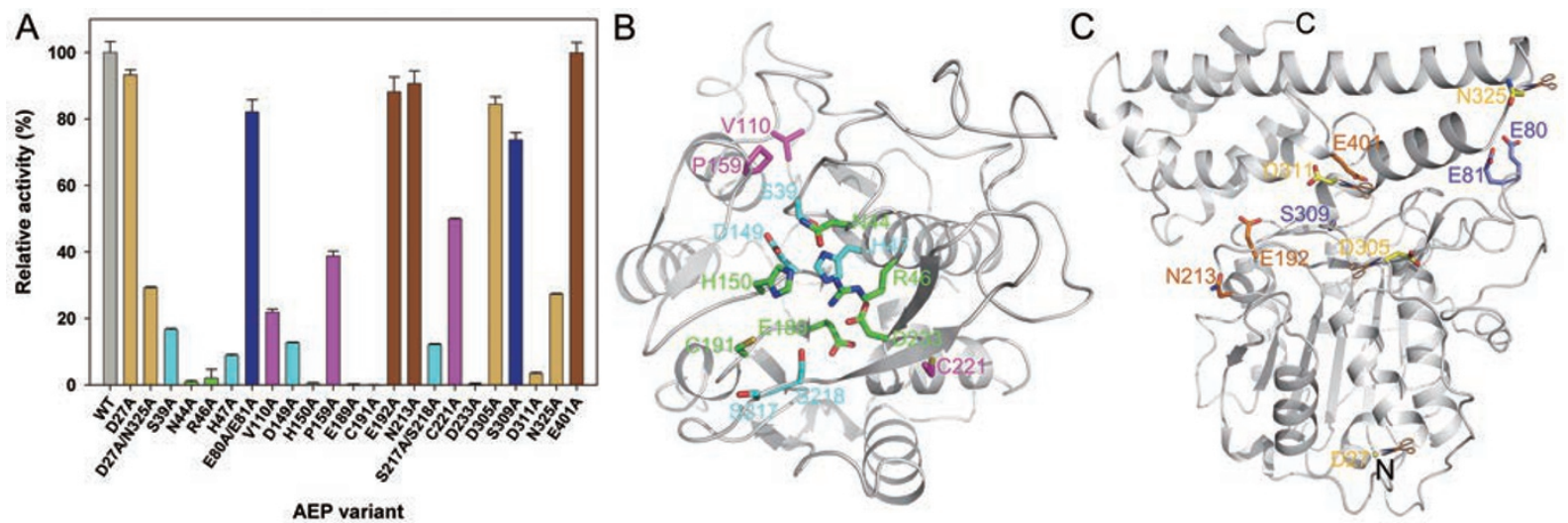

Figure 4 Mutagenesis studies of conserved AEP residues in the active site. (A) The relative activities of the indicated AEP variants were calculated relative to the activity of WT AEP (100\%; grey). WT AEP and all the mutants were first activated at $\mathrm{pH} 3.5$ overnight at $16{ }^{\circ} \mathrm{C}$ followed by the determination of the relative activities under the conditions described in the Materials and Methods. The mutants were divided into six groups (indicated by six different colors) according to their relative activities and were mapped onto the structures of the AEP core domain (B) and pro-AEP (C). 
undergo autoproteolytic maturation in an acidic buffer [21]. To further confirm the maturation ability of C191A, we repeated the maturation experiment at three different $\mathrm{pH}$ values $(4.5,4.0$ and 3.5). C191A was not digested to

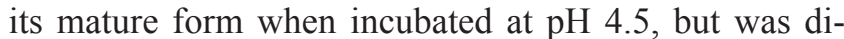
gested to its mature form when incubated at $\mathrm{pH} 4.0$ or 3.5 (Supplementary information, Figure S10A). This result suggests that C191 may not be involved in the autoproteolytic maturation, but is important for the cleavage of the AEP substrate. In contrast, H150A and D233A, which also showed little enzymatic activities, could not be autoproteolytically converted to their mature forms at $\mathrm{pH}$ values of 4.5 and 4.0 (Supplementary information, Figure S7C and S7E). Furthermore, the D233A mutant was not converted to its mature form even when incubated at $\mathrm{pH}$ 3.5 for 48 h (Supplementary information, Figure S10B). To further investigate the mechanism for the inability of the D233A mutant to undergo autoproteolysis, we determined the crystal structure of the pro-AEP D233A mutant at a resolution of $2.70 \AA$ (Supplementary information, Figure S11). The structure of the mutant closely mirrored that of WT pro-AEP with a main-chain RMSD of $0.42 \AA$ over 385 residues (Supplementary information, Figure S5D). In the structure of the WT pro-AEP, D233 lies in the vicinity of the catalytically critical residues. However, there is no noticeable difference between the structures of the D233A mutant and WT AEP. Perhaps D233 plays a critical role in the relay of the protons or charges that are essential for the autoproteolysis reaction.

Taken together, the above results suggest that although H150 and D233 are essential for autoproteolytic maturation, N44, R46, E189 and C191 are not required for the maturation of AEP. However, all of these residues are critical for the cleavage of the peptide substrate. Additionally, WT AEP and the N44A mutant were overexpressed in HEK293T cells, and the cell lysates were harvested for the endopeptidase activity assay using ZAAN-NHMec as the substrate. The result confirmed that the activity of N44A mutant was dramatically decreased compared with that of WT AEP (Supplementary information, Figure S10C).

\section{Residues involved in the re-ligation process of AEP}

To identify the residues involved in the reverse process that converts partially activated AEP to the proenzyme form, we performed an overnight incubation of individual AEP mutants in buffers of $\mathrm{pH} 4.5$ and 4.0. Then, the $\mathrm{pH}$ was adjusted to neutral $\mathrm{pH}$ by adding $1.0 \mathrm{M}$ Tris$\mathrm{HCl}, \mathrm{pH} 8.1$, and the samples were incubated overnight at $16{ }^{\circ} \mathrm{C}$ followed by SDS-PAGE analyses (Supplementary information, Figure S7A-S7G). The E80A/E81A, P159A, N213A, C221A and D305A mutants that were activated at $\mathrm{pH} 4.5$ did not revert to the pro-AEP form when the $\mathrm{pH}$ was increased. The N213A mutant was one of the mutants that exhibited a level of enzymatic activity similar to that of the WT but failed to revert to the pro-AEP form. The endopeptidase activity of N213A was further confirmed by overexpression in HEK293T cells (Supplementary information, Figure S10C). Based on the pro-AEP structure, we speculated that the N213A mutation resulted in the breakage of a hydrogen bond between N213 and E216; this minor structural change may affect the re-ligation process of AEP without affecting its endopeptidase activity.

Interestingly, while $\mathrm{WT} \mathrm{AEP}_{\mathrm{pH} 4.0}$ was not reversed to the proenzyme form, the N44A, D27A/N325A, N325A and $\mathrm{D} 311 \mathrm{~A}$ mutants that were activated at $\mathrm{pH} 4.0$ could return to their pro-AEP forms when the $\mathrm{pH}$ was neutralized (Supplementary information, Figure S7AS7G). Among these residues, D27, N325 and D311 are autocleavage sites, and their mutations may somehow increase AEP resistance to proteolytic cleavage, thereby probably decreasing their maturation $\mathrm{pH}$. Therefore, the corresponding mutant proteins retained the ability to be re-ligated even after activation at $\mathrm{pH}$ below 4.5. In addition to the mutants involving autocleavage sites, the N44A mutant also exhibited re-ligation activity when maturated at $\mathrm{pH} 4.0$. To further delineate the re-ligation activity of the N44A mutant, it was initially activated at $\mathrm{pH} 3.0$ or 4.5 followed by the re-ligation test in neutralized buffers. As expected, the N44A mutant activated at $\mathrm{pH} 4.5$ reverted to pro-AEP when the $\mathrm{pH}$ was neutralized; however, it failed to return to the proenzyme form if it was activated at $\mathrm{pH} 3.0$ (Supplementary information, Figure S12A). The H150A and D233A mutants, which are incapable of self-maturation, did not return to the pro-AEP form after they were maturated by WT AEPmediated proteolysis, indicating that $\mathrm{H} 150$ and D233 are also important for the AEP re-ligation process (Supplementary information, Figure S12B).

\section{A proposed model of inhibition of AEP endopeptidase activity by cystatin $C$}

Cystatin $\mathrm{C}$ has been shown to inhibit mammalian AEP and other cysteine endopeptidases; however, the inhibition mechanism is not fully understood. To study the nature of the interactions between AEP and cystatin $\mathrm{C}$, we co-purified and characterized the $\mathrm{AEP} /$ cystatin $\mathrm{C}$ complex. Human cystatin C (h-cystatin C) was expressed in $E$. coli and prepared as previously described $[28,29]$. The h-cystatin $\mathrm{C}$ inhibits the endopeptidase activity of mouse AEP (m-AEP hereafter) against the peptide substrate ZAAN-NHMec in a dose-dependent manner (Figure 5A). After verification that h-cystatin $\mathrm{C}$ inhibited $\mathrm{m}$-AEP, we 
mixed pro-m-AEP with $\mathrm{h}$-cystatin $\mathrm{C}$ at a $1: 2$ ratio and exposed the sample to buffers of $\mathrm{pH} 4.5$ and 7.5. The two mixtures were incubated overnight at $4{ }^{\circ} \mathrm{C}$ prior to the SEC analysis. Unexpectedly, m-AEP and h-cystatin $\mathrm{C}$ were eluted as two separate peaks in the SEC profiles of both mixtures, indicating that $\mathrm{m}$-AEP and h-cystatin $\mathrm{C}$ did not form complexes at either $\mathrm{pH} 4.5$ or 7.5. Next, we mixed h-cystatin $\mathrm{C}$ and fully activated m-AEP (activated at $\mathrm{pH} 3.5$ ) and incubated the mixture overnight at $16{ }^{\circ} \mathrm{C}$ for complex formation. Under these conditions, only $\mathrm{m}$ AEP was eluted during SEC and h-cystatin $C$ was not detected (Figure 5B). The disappearance of h-cystatin $\mathrm{C}$ prompted us to examine whether the m-AEP degraded hcystatin C. SDS-PAGE analysis of the mixture of fully activated $\mathrm{m}$-AEP with h-cystatin $\mathrm{C}$ clearly indicated that the degradation of h-cystatin $\mathrm{C}$ occurred in a dosedependent manner (Figure 5C).

To determine whether the cleavage of h-cystatin $\mathrm{C}$ by $\mathrm{m}$-AEP was due to a species discrepancy, we examined the intra- and interspecies interactions between AEP and cystatin $\mathrm{C}$ from human and mouse, including h-AEP vs h-cystatin $\mathrm{C}$, h-AEP vs m-cystatin $\mathrm{C}$, m-AEP vs $\mathrm{m}$ cystatin $\mathrm{C}$ and $\mathrm{m}$-AEP vs h-cystatin $\mathrm{C}$. Interestingly, AEP-mediated degradation of cystatin $\mathrm{C}$ was observed in all the analyses (Figure 5D-5G). In summary, these data suggest that cystatin $\mathrm{C}$ functions as an AEP substrate and likely inhibits AEP activity through competition with other AEP substrates.

Pig AEP and h-cystatin C were reported to form a stable complex and were co-eluted during SEC [8]. As human and pig AEPs share high sequence identity (84.8\%), we speculated that pig AEP may also degrade h-cystatin C. Indeed, as shown in Figure 5H, h-cystatin $\mathrm{C}$ was digested by pig AEP with a nearly identical efficiency as that of the human AEP. Cystatin C was also reported to inhibit a variety of other cysteine proteases, such as cathepsins B, $\mathrm{H}, \mathrm{K}, \mathrm{L}$ and $\mathrm{S}[30,31]$. To investigate whether cystatin $\mathrm{C}$ inhibits cathepsins via a similar mechanism, mouse cathepsins B, S and L were activated and their degradative activities towards cystatin $\mathrm{C}$ were determined. The activities of cathepsins $\mathrm{B}$ and $\mathrm{S}$ were confirmed using the fluorogenic peptide substrates Z-Leu-Arg-AMC and Mca-RPKPVENval-WRK(Dnp)-NH2, respectively (Supplementary information, Figure S13A and S13B). Therefore, the active cathepsins were used to digest h-cystatin C. Human cystatin C was not digested by cathepsin B, S, or L, but was digested by a same amount of human AEP (Supplementary information, Figure S13C-S13E).

To further confirm the specific digestion of h-cystatin $\mathrm{C}$ by $\mathrm{m}$-AEP and to investigate the cleavage sites on h-cystatin $\mathrm{C}, \mathrm{N}$-terminal amino acid sequencing was performed to analyze the cleaved bands of h-cystatin $\mathrm{C}$ obtained from SDS-PAGE gel (Figure 5D). Five unique $\mathrm{N}$-terminal sequences were obtained: four sequences contained AEP cleavage sites (three Asp residues and one Asn residue) and one represented the $\mathrm{N}$-terminal five residues (MDIGI) of the recombinant cystatin $\mathrm{C}$ (Figure 5I). The identified cleavage sites on cystatin $\mathrm{C}$ were mapped onto the cystatin C structure (PDB ID: 1TIJ) (Figure 5I). Intriguingly, although cystatin $\mathrm{C}$ could inhibit the endopeptidase activity of AEP and was digested by AEP, the presence of cystatin $\mathrm{C}$ did not affect the religation activity of AEP (Supplementary information, Figure $\mathrm{S} 12 \mathrm{C}$ ). Thus, cystatin $\mathrm{C}$ may regulate the activity of AEP through competition with other substrates for the AEP active site.

\section{Discussion}

Pro-AEP is known to undergo auto-proteolytic maturation in acidic environments, and $\mathrm{AEP}_{\mathrm{pH} 7.5}$ was fully activated when incubated at $\mathrm{pH} 3.5$ (Figure 1C). Activation coincided with a shift of the protein bands observed in SDS-PAGE analysis (Figure 1D). In this study, we demonstrated that the auto-proteolytic maturation was reversible when pro-m-AEP was partially activated at a $\mathrm{pH} \geq$ 4.5. This partially activated AEP was reversed back into its inactive, proenzyme form when incubated at $\mathrm{pH} 7.5$ (Figure 3). The crystal structure of mouse $\mathrm{AEP}_{\mathrm{pH} 4.5}$ (crystallized at $\mathrm{pH} 8.5$ ) revealed a structure of the pro-AEP, and thereby independently confirmed the religation of the cleaved peptide bonds in the partially activated AEP (Figure 2D). Extensive interactions between the cap and the core domains may aid in securing and repositioning the cap during the religation process. WT AEP that was exposed to a $\mathrm{pH}$ below 4.0 was not reversed to its proenzyme form, which may be due to the disassociation of the cap domain from the core domain with a subsequent degradation of the cap domain at a lower $\mathrm{pH}$.

Concerning the mechanism for the reversible activation and maturation of AEP, our results suggest that an intramolecular complex is formed between the partially cleaved core and cap domains at $\mathrm{pH}$ 4.5. The peptide bond was cleaved through a cross-proteolytic process in which the key catalytic residues H150 and D233, but not C191, were involved. According to the principle of microscopic reversibility, we propose that the peptide bond reformation may also be mediated by the identical group of catalytic residues in the intermolecular complex. The observations of the cleavage at $\mathrm{pH} 4.5$ and the religation at a $\mathrm{pH}$ above 7.0 suggest an extraordinary protonation effect on the relative free energy between the partially activated, cleaved complex and pro-AEP. In other words, we hypothesized that protonation of the N- 
A
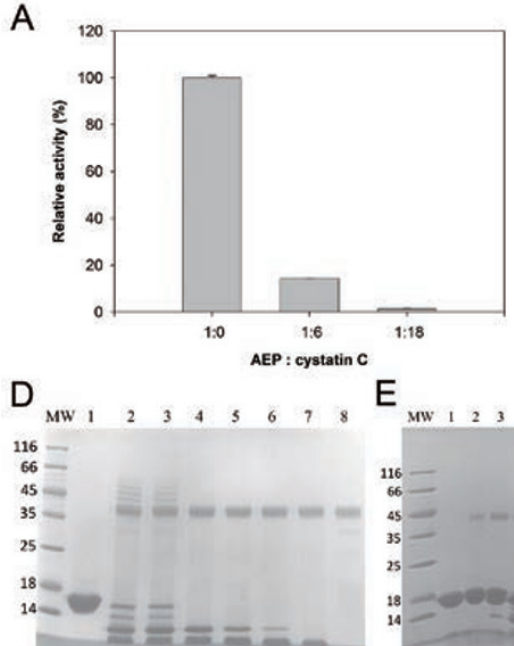

$E_{M W} \begin{array}{lllllllll}1 & 2 & 3 & 4 & 5\end{array}$
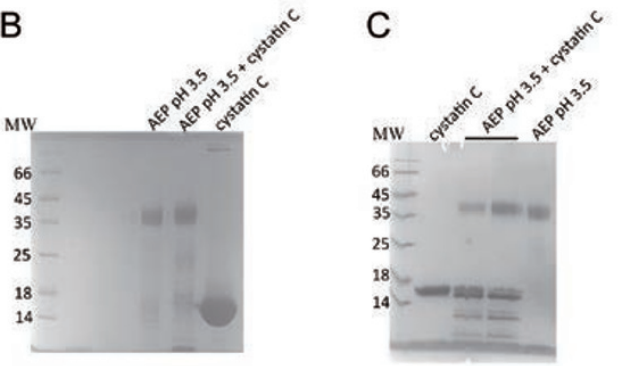

$F_{\text {MW }}, 2,3,4,5,7,8, G$
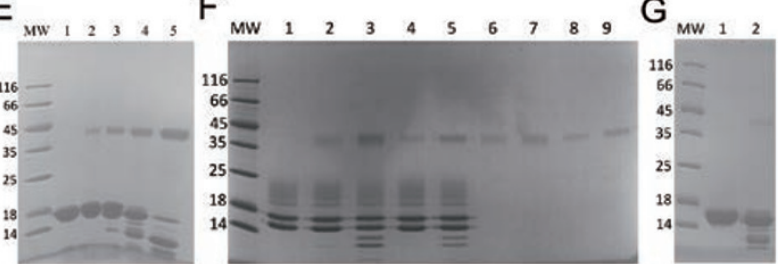

$\mathrm{H}$

Cystatin C original signal peptide

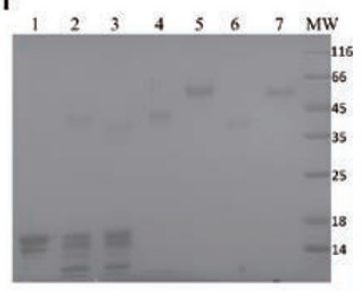

Figure 5 A proposed model for the inhibition of AEP activity by cystatin C. (A) Human cystatin $C$ inhibited the activity of mouse $\mathrm{AEP}_{\mathrm{pH} 3.5}$ in a dose-dependent manner. The enzymatic activity of AEP was measured by using the methods described in Figure 4A. (B) SEC combined with SDS-PAGE analysis for testing the complex formation between mature m-AEP and human cystatin C. Mature AEP and cystatin $C$ were mixed at a $1: 2$ molar ratio and were incubated overnight at $16{ }^{\circ} \mathrm{C}$ for complex formation. The sample was loaded onto a Superdex 200 column. Only AEP was eluted from the SEC, whereas cystatin $\mathrm{C}$ was not detected. The peak fraction was analyzed by SDS-PAGE analysis. (C) Human cystatin $C$ was gradually degraded by mature m-AEP. Mature AEP and human cystatin $\mathrm{C}$ (at a molar ratio of approximately $1: 20$ and 1:7) were incubated overnight at $16{ }^{\circ} \mathrm{C}$ and analyzed using SDS-PAGE analysis. (D) Human cystatin $\mathrm{C}$ was degraded by mature human AEP in a time-dependent manner at $25^{\circ} \mathrm{C}$. Lane 1 : human cystatin $\mathrm{C}$, $5.0 \mu \mathrm{g}$; loading control. Lanes 2-7: human cystatin $\mathrm{C}$ was degraded by mature human AEP after an incubation of $1 \mathrm{~min}, 30 \mathrm{~min}, 1$ h, 2 h, $4 \mathrm{~h}$ and $8 \mathrm{~h}$, respectively. Lane 8: mature human AEP, $2.5 \mu \mathrm{g}$; loading control. The unique bands of human cystatin $\mathrm{C}$ were further analyzed using $\mathrm{N}$-terminal amino acid sequencing. (E) Human cystatin $\mathrm{C}$ was degraded by mature human AEP in a dosedependent manner. All the incubations were performed for 5 min at $25^{\circ} \mathrm{C}$. Lane 1: human cystatin $\mathrm{C}, 5.0 \mu \mathrm{g}$; loading control. Lanes 2-5: human cystatin $C$ was degraded by gradually increased amounts of mature human AEP $(0.25,0.5,1.0$ and $2.5 \mu \mathrm{g})$. (F) Mouse cystatin C, which was expressed in HEK293 cells, was cleaved by mouse and human AEPs. All the incubations were performed for 5 min at $25^{\circ} \mathrm{C}$. Lane 1: mouse cystatin C, $2.0 \mu \mathrm{g}$; loading control. Lanes 2 and 3: mouse cystatin $\mathrm{C}$ was degraded by mature mouse AEPs ( 0.5 and $1.0 \mu \mathrm{g}$, respectively). Lanes 4 and 5 : mouse cystatin $C$ was degraded by mature human AEPs (0.5 and 1.0 $\mu \mathrm{g}$, respectively). Lanes 6 and 7: loading controls of mature mouse AEP for lanes 2 and 3. Lanes 8 and 9: loading controls of mature human AEP for lanes 4 and 5. (G) Human cystatin $C$ was degraded by mature mouse AEP. Lane 1: human cystatin $C, 5.0 \mu \mathrm{g}$; loading control. Lane 2: human cystatin $\mathrm{C}$ was degraded by $0.25 \mu \mathrm{g}$ of mature mouse AEP after an incubation of $1 \mathrm{~min}$ at $25^{\circ} \mathrm{C}$. (H) Human cystatin $\mathrm{C}$ was degraded by activated pig AEP. Lane 1: human cystatin C, $3.3 \mu \mathrm{g}$; loading control. Lane 2: human cystatin $\mathrm{C}$ was degraded by $0.33 \mu \mathrm{g}$ of activated pig AEP after an incubation of $5 \mathrm{~min}$ at $16{ }^{\circ} \mathrm{C}$. Lane 3 : human cystatin $\mathrm{C}$ was degraded by $0.33 \mu \mathrm{g}$ of mature human AEP after an incubation of $5 \mathrm{~min}$ at $16^{\circ} \mathrm{C}$. Lanes 4 and 5 : pig mature AEP and pro-AEP. Lanes 6 and 7: human mature AEP and pro-AEP. (I) The N-terminal amino acid sequencing results of the cleaved bands of human cystatin $\mathrm{C}$ obtained from $\mathbf{D}$. Human endogenous and recombinant cystatin $\mathbf{C}$ amino acid sequences are shown. The cleaved bands of the recombinant human cystain $\mathrm{C}$ were analyzed using $\mathrm{N}$-terminal amino acid sequencing. The pelB leader sequence can be cleaved by signal peptidase in E. coli. In the five unique sequences (red), three Asp (underlined, magenta) residues and one Asn residue (underlined, black) represent AEP cleavage sites. The three Asp residues are indicated in the structure of human cystatin C (PDB ID: $1 \mathrm{TIJ}$ ) as magenta sticks. The $\mathrm{N}$-terminal five residues (MDIGI) of recombinant cystatin $\mathrm{C}$ were also identified by $\mathrm{N}$-terminal amino acid sequencing. 
terminal amino group of the cleaved $\mathrm{N}$-fragment was the driving force for the cleavage event at $\mathrm{pH} 4.5$. At basic $\mathrm{pH}$ values, this group should be neutralized and become a strong nucleophile, shifting the equilibrium back to the peptide state. Thus, this protonation-dependent free energy shifting model can explain the reversible activation and religation of AEP. Further elucidation of the physical details of this model requires the aid of computational energy analysis.

The structural basis for AEP activation at lower $\mathrm{pH}$ values was previously not fully understood. In this study, we demonstrated that pro-AEP was bimodular (Figure 2): at a higher $\mathrm{pH}$, the cap domain covers the core domain and sterically obstructs access to the active site, whereas at a lower $\mathrm{pH}$, the cap domain is removed through autoproteolysis. Removal of the cap domain enables substrate access to the catalytic dyad of $\mathrm{H} 150$ and $\mathrm{C} 191$ for the subsequent catalytic cleavage of the peptide substrate. Our crystallographic snapshots of the proenzyme and mature forms of mouse AEP clearly support this mechanism.

Previously, human cystatin $\mathrm{C}$ has been shown to inhibit both the $\mathrm{C} 1$ and the $\mathrm{C} 13$ peptidase families. Specifically, human cystatin C inhibits pig AEP with $K_{i}$ values $<$ $5 \mathrm{nM}$ [8]. Human cystatin $\mathrm{C}$ and pig AEP were reported to form a tight complex and to be co-eluted in a single peak during SEC. Furthermore, there was no apparent degradation of cystatin $C$ in the presence of AEP and an AEP substrate [8]. However, our initial studies on mouse AEP and its inhibition by human cystatin $\mathrm{C}$ indicated that AEP degraded cystatin $\mathrm{C}$ instead of forming a stable complex with cystatin C (Figure 5). Furthermore, AEPmediated cystatin $\mathrm{C}$ cleavage was confirmed in both inter- and intraspecies assays using human and mouse proteins. Thus, cystatin $\mathrm{C}$ functions as an AEP substrate and likely inhibits AEP through competition with other AEP substrates. AEP from pig shares $85 \%$ sequence identity with its homolog from mouse. Our speculation that pig AEP cleaves human cystatin $C$ was also experimentally confirmed (Figure 5H). Interestingly, previous studies indicated that mouse cathepsins could be inhibited by human cystatin $C[30,31]$. However, human cystatin $C$ was not cleaved by mouse cathepsins, indicating that cystatin C may employ a different mechanism to inhibit cathepsins.

While this manuscript was under preparation, Dall et al. [32] reported the crystal structures of human pro-AEP and the active AEP in complex with the substrate analogs Z-Ala-Ala-AzaAsn-chloromethyl ketone (Z-AAN-CMK) and Ac-Tyr-Val-Ala-chloromethyl ketone (Ac-YVADCMK, an irreversible caspase-1 inhibitor). In their study, the $\mathrm{pH}$-dependent activation was proposed, and an unex- pected hidden asparagine (N)-specific carboxypeptidase activity was unveiled. In this study, we demonstrated similar mouse pro-AEP and mature AEP structures (with a main chain RMSD of $1.04 \AA$ between pro-AEPs and $0.49 \AA$ between active AEPs). Additionally, our study demonstrates the following new findings: 1) partially activated AEP can revert to pro-AEP as the $\mathrm{pH}$ is shifted to neutral values if the $\mathrm{pH}$ of the initial activation buffer was $\geq 4.5$, whereas this reversion does not occur if the $\mathrm{pH}$ of the initial activation buffer was $\leq 4.0 ; 2$ ) cystatin $\mathrm{C}$ is a substrate of AEP and probably inhibits AEP through competition with other AEP substrates; and 3) two additional maturation cleavage sites (N332 and D428) were identified that have not been previously reported.

In conclusion, our structure-function studies on AEP conceptually unveiled an interesting, previously unknown intermediate stage at approximately $\mathrm{pH} 4.5$ during auto-proteolytic maturation of AEP, in which the partially activated AEP can either revert to its proenzyme form if the $\mathrm{pH}$ is shifted from acidic $(\geq 4.5)$ to neutral $(\sim 7.5)$ or proceed further into its irreversible, fully activated form if the $\mathrm{pH}$ is further decreased towards 3.5. Hypothetically, such an intermediate stage may function as a buffer zone for the maintenance of an appropriate AEP enzymatic activity. At the intermediate stage, the partially matured AEP may be further activated rapidly if more endopeptidase activity is required, or it may be recycled back to the proenzyme form if a sufficient endopeptidase activity has been achieved. This feature allows the tunable endopeptidase activity of AEP, which may be important for the precise control of the immune system. The physiological significance of this reversible maturation remains to be further investigated.

\section{Materials and Methods}

\section{Cloning, protein expression and purification}

Full-length mouse and human AEP genes were synthesized by Sangon Biotech Co., Ltd. (Shanghai). Mouse and human AEPs fused with $6 \times$ His tags at C-termini were subcloned into the frame of the pFastbac1 vector (Invitrogen) using the EcoRI and XhoI restriction sites. The resultant clone was confirmed using DNA sequencing. Plasmids containing the genes of interest were then transformed into DH10Bac competent cells (Invitrogen), and the recombinant bacmid DNA was isolated and verified according to the Bac-to-Bac Baculovirus Expression System instructions (Invitrogen). Sf9 insect cells were then transfected to generate recombinant baculovirus, and the titer of the baculoviral stock was amplified by infecting the Sf9 insect cells with P1 and P2 viral stocks. AEP was expressed as a secreted protein by infecting the Sf9 insect cells with recombinant baculovirus at an optimal MOI. The culture medium containing the secreted recombinant protein was harvested $72 \mathrm{~h}$ post infection.

For purification, the culture medium from the insect cells that 
contained the target protein was first centrifuged at $12000 \mathrm{rpm}$ at $4{ }^{\circ} \mathrm{C}$ for $30 \mathrm{~min}$ to remove the cells and cell debris, and was then loaded onto HiTrap Ni Fast Flow beads (GE Healthcare) that were previously equilibrated with $50 \mathrm{mM}$ PBS $\left(50 \mathrm{mM} \mathrm{Na}_{2} \mathrm{HPO}_{4}, 10\right.$ $\mathrm{mM} \mathrm{KH} \mathrm{PO}_{4}, 137 \mathrm{mM} \mathrm{NaCl}$ and $\left.2.7 \mathrm{mM} \mathrm{KCl}, \mathrm{pH} 7.4\right)$ at $4{ }^{\circ} \mathrm{C}$. The beads were sequentially washed using $50 \mathrm{mM}$ PBS containing $20 \mathrm{mM}$ and $50 \mathrm{mM}$ imidazole and were then eluted with 50 mM PBS supplemented with $300 \mathrm{mM}$ imidazole. The protein was further purified on a SEC column that was equilibrated with 20 $\mathrm{mM}$ HEPES, $\mathrm{pH} 7.5$ and $150 \mathrm{mM} \mathrm{NaCl}$. The pooled peak fractions $\left(\mathrm{AEP}_{\mathrm{pH} 7.5}\right)$ were concentrated to $13 \mathrm{mg} / \mathrm{ml}$, and aliquots were flash-frozen in liquid nitrogen and stored at $-80{ }^{\circ} \mathrm{C}$ until further use. Mouse and pig AEPs that were expressed in HEK293 cells to confirm functional AEP expression in insect cells were purchased from Sino Biological Inc. (Catalog \#: 50051-M07H and 62001W08H, respectively).

Mutations were designed based on mouse AEP constructs, and mutagenesis was performed using a QuikChange site-directed mutagenesis kit following the manufacturer's instructions (Stratagene). All the recombinant plasmids were sequenced to verify the sequences. AEP mutants were expressed and purified in the same manner as that for WT AEP.

\section{Production of cystatin $C$ and GST-TEV-Ub}

For human cystatin $\mathrm{C}$ expression in $E$. coli, the human cystatin $C$ gene without a signal peptide, $\mathrm{C}$-terminal thrombin cleavage sites, and a $6 \times$ His tag cassette was subcloned into the pET26b vector using BamHI and $\mathrm{XhoI}$ restriction sites. The resultant plasmid was confirmed using DNA sequencing and then transformed into $E$. coli BL21(DE3) competent cells for expression and purification according to previously described methods [28, 29]. Mouse cystatin $\mathrm{C}$ that was expressed in HEK293 cells was purchased from Sino Biological Inc. (Catalog \#: 10439-H08H).

A GST-TEV-Ub expression plasmid was constructed by inserting the ubiquitin $(\mathrm{Ub})$ gene into the pMCSG10 vector, which contained a GST tag and a TEV protease cleavage site [33].

\section{Crystallization}

The full-length mouse AEP produced by insect cells and treated with PNGase F was screened for crystallization conditions immediately after purification, as previously described [34]. Crystallization screening was performed using the sitting-drop-vapor diffusion method and commercial-screening kits from Hampton Research and Emerald BioSystems. A volume of $0.4 \mu \mathrm{l}$ of the protein stock solution was mixed with $0.4 \mu 1$ of reservoir solution using a Mosquito robot (TTP Labtech) and equilibrated against $35 \mu 1$ of reservoir at $16{ }^{\circ} \mathrm{C}$. Diffraction-quality crystals of pro- $\mathrm{AEP}_{\mathrm{pH} 7.5}$ were obtained in a condition containing $0.2 \mathrm{M}$ succinic acid, $\mathrm{pH}$ 7.0 and 20\% PEG 3350. Crystals of native and $\mathrm{Hg}$-derivatized $\mathrm{AEP}_{\mathrm{pH} 4.5}$ were obtained in $0.2 \mathrm{M}$ trimethylamine $\mathrm{N}$-oxide dehydrate, $0.1 \mathrm{M}$ Tris-HCl, pH 8.5 and 20\% PEG 2000. Crystals of active $\mathrm{AEP}_{\mathrm{pH} 3.5}$ were obtained in $0.01 \mathrm{M}$ zinc sulfate, $0.1 \mathrm{M}$ MES, pH 6.7 and 23\% PEG 500. Diffraction-quality crystals of pro-AEP

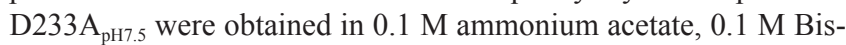
Tris-HCl, pH 5.5 and 17\% PEG 10000.

Data collection, phasing, structure solution and refinement

Crystals were harvested and flash-frozen in liquid nitrogen. The crystals were derivatized by adding a small grain of mercury potassium iodide to the crystallization drop, as previously reported [35], followed by incubation for $4 \mathrm{~h}$. Diffraction data for crystals obtained at pH 7.5 were collected at beamline BL17A at the Photon Factory (KEK, Japan). All other diffraction data were collected at $100 \mathrm{~K}$ using an ADSC Q315 CCD detector at beamline BL17U1 at the Shanghai Synchrotron Radiation Facility (SSRF). All datasets were indexed, integrated and scaled using the HKL2000 software package [36]. The initial phases of $\mathrm{AEP}_{\mathrm{pH} 4.5}$ were determined using the $\mathrm{X}^{2} \mathrm{DF}$ structure determination pipeline $[37,38]$ and the Hg-SAD (single-wavelength anomalous dispersion) method [39], and the initial model was built using Phenix Autobuild [40]. The remaining structures were solved by molecular replacement [41] using the determined $\mathrm{AEP}_{\mathrm{pH} 4.5}$ structure as the search model. The models were manually improved in Coot [42]. Refinement was performed by alternately using REFMAC [43] and Phenix Refine [40]. The statistics for the data collection and refinement are summarized in Table 1.

\section{Autoactivation of AEP and enzymatic activity assay}

Autoactivation of AEP was performed by diluting aliquots of the AEP proenzyme into a buffer containing $0.2 \mathrm{M}$ sodium citrate/ citric acid and $1 \mathrm{mM}$ dithiothreitol that was adjusted to different $\mathrm{pH}$ values. After an overnight incubation at $16^{\circ} \mathrm{C}$, the enzymatic activity of AEP was assessed by transferring aliquots of the autoactivation reaction to the AEP assay buffer $(40 \mathrm{mM}$ citric acid, $121 \mathrm{mM} \mathrm{Na}_{2} \mathrm{HPO}_{4}, \mathrm{pH} 5.8$, containing $1 \mathrm{mM}$ dithiothreitol, $1 \mathrm{mM}$ EDTA and $0.1 \%$ CHAPS), which included $20 \mu \mathrm{M}$ Z-Ala-Ala-AsnNHMec (Z-AAN-NHMec) (Bachem) as the substrate [21]. The rate of formation of the product was monitored in a fluorometer at $25^{\circ} \mathrm{C}$. The excitation and emission wavelengths were 360 and 460 nm, respectively.

For the enzymatic activity of AEP in the HEK293T cell lines, various AEP constructs were transfected into the cells. Autoactivation of AEP was achieved by equilibrating the cell lysates in buffers at $\mathrm{pH}$ 4.0. The enzymatic activity assays were performed as previously described.

Purified protein substrates of AEP, such as cystatin C and GSTTEV-Ub, were mixed with activated AEP in a reaction buffer $(20$ $\mathrm{mM}$ HEPES, $\mathrm{pH} 7.5$ and $150 \mathrm{mM} \mathrm{NaCl}$ ) at $16^{\circ} \mathrm{C}$ or $25^{\circ} \mathrm{C}$ for a suitable length of time.

For the conversion of partially activated AEP back to the proenzyme form, the $\mathrm{pH}$ of the samples was adjusted back to a neutral $\mathrm{pH}$ by adding moderate amounts of $1.0 \mathrm{M}$ Tris- $\mathrm{HCl}, \mathrm{pH} 8.1$, and the samples were incubated overnight at $16{ }^{\circ} \mathrm{C}$.

The mouse cathepsins B, S and L were purchased from Sino Biological Inc (Catalog \#: 50084-M08H, 50769-M08H, and $50015-\mathrm{M} 08 \mathrm{H}$, respectively) and were activated according to the manufacturer's assay procedures. The bioactivity of cathepsins B and $\mathrm{S}$ were measured by their abilities to cleave the fluorogenic peptide substrates Z-LR-AMC (R\&D Systems, Catalog \#: ES008) and Mca-RPKPVENval-WRK(Dnp)-NH2 (R\&D Systems, Cata$\log$ \#: ES002), respectively. Human cystatin $C$ and the activated cathepsins were mixed in the assay buffer for $1 \mathrm{~min}, 5 \mathrm{~min}, 30$ min, $1 \mathrm{~h}$ and $4 \mathrm{~h}$ at $16{ }^{\circ} \mathrm{C}$ or $25^{\circ} \mathrm{C}$ and analyzed using SDS-PAGE analysis.

\section{Small-angle $X$-ray scattering (SAXS)}

SAXS data for $\mathrm{AEP}_{\mathrm{pH} 4.0}(20 \mathrm{mM}$ citric acid, $\mathrm{pH} 4.0$, and 150 $\mathrm{mM} \mathrm{NaCl})$ and $\mathrm{AEP}_{\mathrm{pH} 7.5}(20 \mathrm{mM}$ HEPES, $\mathrm{pH} 7.5$, and $150 \mathrm{mM}$ 
$\mathrm{NaCl}$ ) were collected on the SIBYLS beamline at the Advanced Light Source (ALS), Lawrence Berkeley National Laboratory, and the data were treated as previously described $[44,45]$. Briefly, each sample was measured at three exposures $(0.5,1.0$, and $6.0 \mathrm{sec})$ and three concentrations $(2.5,5.0$, and $10.0 \mathrm{mg} / \mathrm{ml})$ at $10{ }^{\circ} \mathrm{C}$ to exclude aggregation and radiation-damage effects. Both the maximum dimension (Dmax) and the MW derived from the SAXS P(r) function for $\mathrm{AEP}_{\mathrm{pH} 7.5}$ were larger than those of $\mathrm{AEP}_{\mathrm{pH} 4.0}$ (Dmax: $130 \pm$ $5 \AA$ compared with $70 \pm 5 \AA$; MW: $97.5 \pm 2.4 \mathrm{kDa}$ compared with $33.1 \pm 0.7 \mathrm{kDa}$, respectively). Thus, AEP exists as a homodimer in solution at $\mathrm{pH} 7.5$ but as a monomer at $\mathrm{pH}$ 4.0. CRYSOL [46] was then used to confirm the most reasonable conformation. Ten individual GASBOR [47] calculations with P2 symmetry as a restraint were performed to construct shapes for $\mathrm{AEP}_{\mathrm{pH7.5}}$. The resultant solution model, within which the dimer model fits well, had an acceptable Chi value of $1.49 \pm 0.07$. For $\mathrm{AEP}_{\mathrm{pH} 4.0}$, no symmetry constraint was used, and the final Chi value was $0.90 \pm 0.09$.

\section{$N$-terminal amino acid sequencing}

$\mathrm{N}$-terminal amino acid sequencing was performed as previously described [48]. Briefly, the protein was first fractionated using SDS-PAGE and then electrophoretically transferred to a polyvinylidene difluoride (PVDF) membrane for $1 \mathrm{~h}(300 \mathrm{~mA})$ in an ice bath using a Bio-Rad apparatus. The protein band was visualized by staining with Coomassie Brilliant Blue ( $0.1 \%$ Coomassie Brilliant Blue R-250 in 1.0\% acetic acid and 40\% methanol) and excised to air dry. The PVDF membrane containing the target band was digested and extracted. Finally, the protein was sequenced on an automated protein sequencer (ABI Procise 491) to identify the first four or five amino acids in the N-terminus.

\section{Circular dichroism (CD) spectroscopy}

CD spectra were acquired on a Chirascan CD Spectrometer (Applied Photophysics). Freshly prepared WT and mutant AEP proteins were adjusted to $0.2 \mathrm{mg} / \mathrm{ml}$ in $40 \mathrm{mM}$ Tris- $\mathrm{HCl}, \mathrm{pH} 7.5$, prior to the measurements. Wavelength spectra were recorded at $20{ }^{\circ} \mathrm{C}$ using a $0.1-\mathrm{cm}$ path length cuvette. Each scan was obtained by recording every $1 \mathrm{~nm}$ with a bandwidth of $1 \mathrm{~nm}$ between the wavelength ranges of 200-260 $\mathrm{nm}$.

\section{Western blot analysis}

Western blot analysis was preformed according to the standard protocol and detection was performed using an HRP-conjugated mouse anti-His antibody (Sigma, USA) [29]. Immunoreactive bands were visualized using Enhanced Chemiluminescence (ECL) reagents (Santa Cruz, USA) according to the manufacturer's instructions.

\section{Synthesis of the AEP inhibitor AAN-CMK}

The AEP inhibitor AAN-CMK was synthesized as previously described [19].

\section{Statistical analysis}

The significance of differences between groups exhibiting similar variance was evaluated using Student's $t$-test.

\section{$P D B$ deposition}

The coordinates and structure factors of $\mathrm{AEP}_{\mathrm{pH} 4.5}, \mathrm{AEP}_{\mathrm{pH} 7.5}$, $\mathrm{AEP}_{\mathrm{pH} 3.5}$ and $\mathrm{AEP}_{\mathrm{pH} 7.5} \mathrm{D} 233 \mathrm{~A}$ have been deposited in $\mathrm{PDB}$ under the accession codes $4 \mathrm{NOM}, 4 \mathrm{NOK}, 4 \mathrm{NOJ}$ and $4 \mathrm{NOL}$, respectively.

\section{Acknowledgments}

The authors thank the staff at the synchrotron beamlines (17U of the SSRF, 17A of KEK, and SIBYLS of the ALS) for their assistance with the X-ray diffraction and solution X-ray scattering data collection. This work was supported by the Ministry of Science and Technology of China (2014CB910400, 2013CB911103 and 2011CB911103), the Ministry of Health of China (2013ZX10004602 ) and the National Natural Science Foundation of China ( 31330019, 31200559, 91313301 and 31300613).

\section{References}

1 Chen JM, Dando PM, Rawlings ND, et al. Cloning, isolation, and characterization of mammalian legumain, an asparaginyl endopeptidase. J Biol Chem 1997; 272:8090-8098.

2 Chen JM, Dando PM, Stevens RA, Fortunato M, Barrett AJ. Cloning and expression of mouse legumain, a lysosomal endopeptidase. Biochem J 1998; 335:111-117.

3 Chen JM, Rawlings ND, Stevens RA, Barrett AJ. Identification of the active site of legumain links it to caspases, clostripain and gingipains in a new clan of cysteine endopeptidases. FEBS Lett 1998; 441:361-365.

4 Chan CB, Abe M, Hashimoto N, et al. Mice lacking asparaginyl endopeptidase develop disorders resembling hemophagocytic syndrome. Proc Natl Acad Sci USA 2009; 106:468-473.

5 Morita Y, Araki H, Sugimoto T, et al. Legumain/asparaginyl endopeptidase controls extracellular matrix remodeling through the degradation of fibronectin in mouse renal proximal tubular cells. FEBS Lett 2007; 581:1417-1424.

6 Chen JM, Fortunato M, Stevens RA, Barrett AJ. Activation of progelatinase A by mammalian legumain, a recently discovered cysteine proteinase. Biol Chem 2001; 382:777-783.

7 Sarandeses CS, Covelo G, Diaz-Jullien C, Freire M. Prothymosin alpha is processed to thymosin alpha 1 and thymosin alpha 11 by a lysosomal asparaginyl endopeptidase. J Biol Chem 2003; 278:13286-13293.

8 Alvarez-Fernandez M, Barrett AJ, Gerhartz B, et al. Inhibition of mammalian legumain by some cystatins is due to a novel second reactive site. J Biol Chem 1999; 274:19195-19203.

9 Hsing LC, Rudensky AY. The lysosomal cysteine proteases in MHC class II antigen presentation. Immunol Rev 2005; 207:229-241.

10 Manoury B, Hewitt EW, Morrice N, et al. An asparaginyl endopeptidase processes a microbial antigen for class II MHC presentation. Nature 1998; 396:695-699.

11 Antoniou AN, Blackwood SL, Mazzeo D, Watts C. Control of antigen presentation by a single protease cleavage site. Immunity 2000; 12:391-398.

12 Ewald SE, Lee BL, Lau L, et al. The ectodomain of Toll-like receptor 9 is cleaved to generate a functional receptor. Nature 2008; 456:658-662.

13 Bauer S. Toll-like receptor 9 processing: the key event in Tolllike receptor 9 activation? Immunol Lett 2013; 149:85-87.

14 Ewald SE, Engel A, Lee J, et al. Nucleic acid recognition by Toll-like receptors is coupled to stepwise processing by 
cathepsins and asparagine endopeptidase. J Exp Med 2011; 208:643-651.

15 Park B, Brinkmann MM, Spooner E, et al. Proteolytic cleavage in an endolysosomal compartment is required for activation of Toll-like receptor 9. Nat Immunol 2008; 9:1407-1414.

16 Sepulveda FE, Maschalidi S, Colisson R, et al. Critical role for asparagine endopeptidase in endocytic Toll-like receptor signaling in dendritic cells. Immunity 2009; 31:737-748.

17 Saska I, Gillon AD, Hatsugai N, et al. An asparaginyl endopeptidase mediates in vivo protein backbone cyclization. $J$ Biol Chem 2007; 282:29721-29728.

18 Mylne JS, Chan LY, Chanson AH, et al. Cyclic peptides arising by evolutionary parallelism via asparaginyl-endopeptidase-mediated biosynthesis. Plant Cell 2012; 24:2765-2778.

19 Niestroj AJ, Feussner K, Heiser U, et al. Inhibition of mammalian legumain by Michael acceptors and AzaAsn-halomethylketones. Biol Chem 2002; 383:1205-1214.

20 Chen JM, Fortunato M, Barrett AJ. Activation of human prolegumain by cleavage at a $\mathrm{C}$-terminal asparagine residue. Biochem J 2000; 352:327-334.

21 Li DN, Matthews SP, Antoniou AN, Mazzeo D, Watts C. Multistep autoactivation of asparaginyl endopeptidase in vitro and in vivo. J Biol Chem 2003; 278:38980-38990.

22 Dall E, Brandstetter H. Activation of legumain involves proteolytic and conformational events, resulting in a context- and substrate-dependent activity profile. Acta Crystallogr Sect F Struct Biol Cryst Commun 2012; 68:24-31.

23 Holm L, Rosenstrom P. Dali server: conservation mapping in 3D. Nucleic Acids Res 2010; 38:W545-W549.

24 Laskowski RA, Watson JD, Thornton JM. ProFunc: a server for predicting protein function from 3D structure. Nucleic Acids Res 2005; 33:W89-W93.

25 Walters J, Schipper JL, Swartz P, Mattos C, Clark AC. Allosteric modulation of caspase 3 through mutagenesis. Biosci Rep 2012; 32:401-411.

26 Wilson KP, Black JA, Thomson JA, et al. Structure and mechanism of interleukin-1 beta converting enzyme. Nature 1994; 370:270-275.

27 Kuroyanagi M, Nishimura M, Hara-Nishimura I. Activation of Arabidopsis vacuolar processing enzyme by self-catalytic removal of an auto-inhibitory domain of the C-terminal propeptide. Plant Cell Physiol 2002; 43:143-151.

28 Dalboge H, Jensen EB, Tottrup H, et al. High-level expression of active human cystatin $\mathrm{C}$ in Escherichia coli. Gene 1989; 79:325-332.

29 Ouyang S, Gong B, Li JZ, et al. Structural insights into a human anti-IFN antibody exerting therapeutic potential for systemic lupus erythematosus. J Mol Med (Berl) 2012; 90:837846.

30 Hall A, Ekiel I, Mason RW, et al. Structural basis for different inhibitory specificities of human cystatins $\mathrm{C}$ and D. Biochemistry 1998; 37:4071-4079.

31 Lutgens SP, Cleutjens KB, Daemen MJ, Heeneman S. Cathepsin cysteine proteases in cardiovascular disease. Faseb $J$ 2007; 21:3029-3041.

32 Dall E, Brandstetter H. Mechanistic and structural studies on legumain explain its zymogenicity, distinct activation pathways, and regulation. Proc Natl Acad Sci USA 2013;
110:10940-10945.

33 Stols L, Zhou M, Eschenfeldt WH, et al. New vectors for coexpression of proteins: structure of Bacillus subtilis ScoAB obtained by high-throughput protocols. Protein Expr Purif 2007; 53:396-403.

34 Liang W, Ouyang S, Shaw N, et al. Conversion of D-ribulose 5-phosphate to D-xylulose 5-phosphate: new insights from structural and biochemical studies on human RPE. Faseb $J$ 2011; 25:497-504.

35 Mori T, Nishizawa S, Hirohashi Y, et al. Efficiency of G2/ M-related tumor-associated antigen-targeting cancer immunotherapy depends on antigen expression in the cancer stem-like population. Exp Mol Pathol 2012; 92:27-32.

36 Otwinowski Z, Minor W. Processing of X-ray diffraction data collected in oscillation mode. Methods in Enzymology 1997; 276:307-326.

37 Liu ZJ, Lin D, Tempel W, et al. Parameter-space screening: a powerful tool for high-throughput crystal structure determination. Acta Crystallogr D Biol Crystallogr 2005; 61:520-527.

$38 \mathrm{Ru} \mathrm{H}$, Zhao L, Ding W, et al. S-SAD phasing study of death receptor 6 and its solution conformation revealed by SAXS. Acta Crystallogr D Biol Crystallogr 2012; 68:521-530.

39 Hendrickson WA. Determination of macromolecular structures from anomalous diffraction of synchrotron radiation. Science 1991; 254:51-58.

40 Adams PD, Afonine PV, Bunkoczi G, et al. PHENIX: a comprehensive Python-based system for macromolecular structure solution. Acta Crystallogr D Biol Crystallogr 2010; 66:213221.

41 McCoy AJ, Grosse-Kunstleve RW, Adams PD, et al. Phaser crystallographic software. J Appl Crystallogr 2007; 40:658674.

42 Emsley P, Lohkamp B, Scott WG, Cowtan K. Features and development of Coot. Acta Crystallogr D Biol Crystallogr 2010; 66:486-501.

43 Murshudov GN, Vagin AA, Dodson EJ. Refinement of macromolecular structures by the maximum-likelihood method. Acta Crystallogr D Biol Crystallogr 1997; 53:240-255.

44 Niu F, Shaw N, Wang YE, et al. Structure of the Leanyer orthobunyavirus nucleoprotein-RNA complex reveals unique architecture for RNA encapsidation. Proc Natl Acad Sci USA 2013; 110:9054-9059.

45 Jiao L, Ouyang S, Liang M, et al. Structure of severe fever with thrombocytopenia syndrome virus nucleocapsid protein in complex with suramin reveals therapeutic potential. $J$ Virol 2013; 87:6829-6839.

46 Schmidt B, Konig S, Svergun D, et al. Small-angle X-ray solution scattering study on the dimerization of the FKBP25mem from Legionella pneumophila. FEBS Lett 1995; 372:169-172.

47 Svergun DI, Petoukhov MV, Koch MH. Determination of domain structure of proteins from X-ray solution scattering. Biophys J 2001; 80:2946-2953.

48 Niu F, Ru H, Ding W, Ouyang S, Liu ZJ. Structural biology study of human TNF receptor associated factor 4 TRAF domain. Protein Cell 2013; 4:687-694.

(Supplementary information is linked to the online version of the paper on the Cell Research website.) 